\title{
An Overlapping Generations Model of Electoral Competition
}

\section{Citation}

Alesina, Alberto, and Stephen E. Spear. 1988. An overlapping generations model of electoral competition. Journal of Public Economics 37(3): 359-379.

\section{Published Version}

doi:10.1016/0047-2727(88)90047-3

\section{Permanent link}

http://nrs.harvard.edu/urn-3:HUL.InstRepos:4553015

\section{Terms of Use}

This article was downloaded from Harvard University's DASH repository, and is made available under the terms and conditions applicable to Other Posted Material, as set forth at http:// nrs.harvard.edu/urn-3:HUL.InstRepos:dash.current.terms-of-use\#LAA

\section{Share Your Story}

The Harvard community has made this article openly available.

Please share how this access benefits you. Submit a story.

Accessibility 
NBER WORKING PAPER SERIES

AN OVERLAPPING GENERATIONS MODEL

OF ELECTORAL COMPETITION

\author{
Alberto Alesina \\ Stephen E. Spear
}

Working Paper No. 2354

\author{
NATIONAL BUREAU OF ECONOMIC RESEARCH \\ 1050 Massachusetts Avenue \\ Cambridge, MA 02138 \\ August 1987
}

Our interest in this topic was stimulated by an observation made by Howard Rosenthal during a session of the Pitt-CMU theory workshop. We are also grateful to the participants of the CMU Political Economy workshop, and to Herschel Grossman for many helpful comments. Spear's work on this paper was supported by a grant SES 8420486 from the Natinal Science Foundation which is gratefully acknowledged. The research reported here is part of the NBER's research program in Financial Markets and Monetary Economics. Any opinions expressed are those of the authors and not those of the National Bureau of Economic Research. 
NBER Working Paper \#2354 August 1987

An Overlapping Generations Model of Electoral Competition

\section{ABSTRACT}

This paper presents a dynamic model of political competition between two "parties" with different policy preferences. A "party" is explicitly modelled as a sequence of overlapping generations of candidates, all of whom face finite decision horizons. In general, there is a conflict between the interests of the individual policymakers and those of the "party", which includes subsequent generations of candidates. We characterize this conflict and suggest a scheme of "intergenerational transfers" within the party which can resolve or mitigate this conflict. The the paper shows how the "overlapping generations" model can be usefully applied to the political arena.

Alberto Alesina

GSIA

Carnegie-Mellon University

Pittsburgh, PA 15213
Stephen Spear

GSIA

Carnegie-Mellon University

Pittsburgh, PA 15213 


\section{Introduction}

One of the most famous results in political economy is that one should observe policy convergence in a two-party system. In particular, if the candidates maximize the likelihood of (re)appointment as suggested by Downs [1957], full convergence of policies results in equilibrium: both parties adopt the same policy. This is the basic message, for example, of the "median voter theorem"1.

The assumption that candidates care only about winning elections, however, is extreme and perhaps overly simple. In general, different policymakers may have different views about policy and/or they may adopt as their own the objective functions of different constituencies with conflicting political or economic interests. In this case, candidates do not view winning an election as their only goal, but also as a means of implementing the policies most preferred by their constituencies. We believe that this view (formalized originally by Wittman [1977]) is more realistic and more general because it can incorporate the case of pure Downsian candidates as a particular (and extreme) case of the broader model. Let us label candidates who are not purely Downsian as "politically motivated".

Wittman [1977; 1983], Calvert [1985] and Chapell-Keech [1986] have shown that if there is uncertainty about the distribution of voters' preferences so that electoral results are uncertain, "politically motivated" candidates may not propose fully convergent platforms to the voters. However Calvert [1985] emphasizes that even if convergence is not complete, the candidates may locate "very close" to each other, certainly much closer than their respective ideal or "bliss" points. Furthermore, if candidates are sufficiently Downsian, even 
full convergence may result in equilibrium.

Alesina [1987a], on the other hand, shows that these results of partial (or complete) convergence are time-inconsistent since candidates cannot credibly pre-commit to electoral platforms. While candidates have an incentive to announce convergent platforms to increase their chances of winning an election, once in office the winning candidate is not committed to her announced platform. Indeed, she has every incentive to follow her most preferred policy. Rational, forward looking voters would account for this ex post incentive and vote accordingly. Thus, if the candidate's tenure in office is finite, the only time-consistent electoral equilibrium is one in which no convergence is possible and the two candidates follow their most preferred policies when in office ${ }^{2}$. This result holds even if the candidates attribute only a very small weight to their policy goals and almost all weight to the goal of winning elections.

This divergence of policies is sub-optimal in the sense that both candidates would benefit from a reduction of this volatility. This sub-optimality arises from two considerations. First, each "party" would prefer that its candidate follow convergent policies, in order to capture (probabilistically) middle voters. Second, society as a whole may suffer from excess volatility of policy, particularly of economic policy. Alesina [1987b] provides an example of the effects of excess volatility of monetary policy for the business cycle. In that model, stochastic changes of policymakers with different preferences on the inflation/unemployment trade-off amplify the effects of the cycle by destabilizing expectations of future policies. ${ }^{3}$ This excess volatility in policymaking can be reduced by several mechanisms; for a survey on this issue, see Alesina-Tabellini [1987]. Alesina [1987a,b], for 
example, has shown how the repeated interaction of two "infinitely lived" parties can sustain partial or complete convergence by means of reputational strategies in an infinitely repeated game. A "party" is identified in this context by an objective function defined over a set of economic or non-economic goals. In these papers, the candidates are completely identified with the party, so that the goals of finite-lived policymakers coincide with those of the long-lived party.

The identification between the "party" and each individual candidate is, however, unrealistic. Thus, this paper moves a step toward a more realistic model of the party. We model the "party" as a sequence of candidates "politically active" in different time periods, accounting explicitly for the fact that individual policymakers hold political office, and that officholders live finite political lives. The existence of a "last period" for the individual policymaker generates a potential conflict between the interests of the individual and those of her party. ${ }^{4}$ In analyzing this model, we will be particularly interested in the question of whether it is possible that finitely-lived policymakers follow "far-sighted" policies, that is, policies which do not maximize their short-run benefits, but maximize the long-run benefits of the "party" or even of society as a whole. Our analysis provides an affirmative answer to this question.

We suggest a transfer scheme wich enforces an equilibrium in wich the policymakers, even in their last period of political life, do not follow their individually most preferred policies. Instead, they adopt policies which enhance the chances of a candidate of their own type (or party) being elected to succeed them. We view the transfer scheme as one in which future presidential candidates alive today (labelled, purely as a matter of 
convenience, "vice-presidents") compensate the "president" currently in office for not locating at her most preferred policy. If the "vice-president" is subsequently elected, her "vice-president" will compensate her for not locating at a most preferred policy, and so on. The amount of compensation (in utility terms) must be sufficient to make the incumbent officeholder indifferent between her most preferred policy ex post and the ex ante optimal policy. With incentives to deviate from the optimal pre-commitment policy thus eliminated, equilibria with pre-commitment become possible.

We note that the possibility of using intergenerational transfers to deal with time-consistency problems was proposed originally by Kotlikoff, Persson and Svensson [1986], although in a different context. In addition, Cremer [1986] has studied how finitely-lived members of an infinitely-lived organization can achieve some degree of cooperation by means of implicitly defined transfers from young agents to old agents in the allocation of effort. 


\section{The ModeI}

We consider an overlapping generations model of political competition. The policymakers have a political life of two periods, where the term "life" will be used to indicate the period of politically active life. A period is identified with a term of office. Thus, there are elections at the beginning of each period. When a policymaker is "young" (i.e. in her first period of life), she can be either a vice-president or out of office. When a policymaker is "old" (i.e. in her second period of life) she can be either president or out of office. Thus, a president cannot be appointed more than once, although it is possible to reinterpret the model to accomodate the possibility of reappointment (see the Appendix). Also, if a policymaker has served as vice president when young, she automatically becomes the candidate of her party for the following presidential elections. We note again that our use of the term vice-president is used purely for convenience to denote future candidates who are currently alive.

The policymakers belong to one of two parties, labelled 1 and 2 . Party 1 represents a constituency with the following objectives defined on the unidimensional policy issue $z \in[0,1]$ for each period:

(1.1a) $\mathrm{W}^{1}=\mathrm{U}(z)$

where $U$ is twice continuously differentiable, and

(1.1b) $\quad \mathrm{U}_{z}\left(\mathrm{x}^{\mathrm{b}}\right)=0$

and 
(I.IC) $\quad U_{z}(z)\{\gtreqless\} 0$ as $z\left\{\lfloor\} x^{b}\right.$.

In addition, we assume that $U(z)$ is strictly concave, so that $U_{z z}(z)<0$ for all $z$. Party 2 represents a constituency with the following objectives in each period:

(1.2a) $\quad W^{2}=V(z)$

where $V$ is twice continuously differentiable, and

(1.2b) $\quad v_{z}\left(y^{b}\right)=0$

and

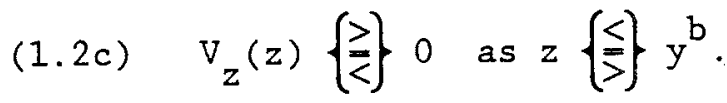

In addition, we assume that $\mathrm{V}_{z z}(z)<0$ for all $z$. The two parties have different bliss points $x^{b}$ and $y^{b}$. To fix ideas, we assume that $x^{b}>y^{b}$.

Thus, each policymaker belongs to one of the two parties and adopts the appropriate objectives. In addition, each candidate attributes a positive utility to holding office per se, regardless of the policy followed when in office. We denote this benefit by $k$ and we assume for simplicity that $k$ is identical for every candidate of either party. Finally, we assume that both candidates discount the future at a rate given by the discount factor $q$ which is assumed to be the same for both candidate types ${ }^{4}$.

Electoral competition occurs as follows. Denote the policies chosen in period $t$ by a president from party $I$ and party 2 by $x_{t}$ and $y_{t}$ respectively. At the end of period $t-1$, candidates announce their platforms for period $t$, 
denoted $x_{t}^{a}$ and $y_{t}^{a}$. Voters are rational and forward-looking. Hence, they form rational expectations of the policies that would be followed by the two candidates if elected. Let us denote these expectations by $x_{t}^{e}$ and $y_{t}^{e}$. These expectations are determined formally as

$$
x_{t}^{e}=E_{t-1}\left(x_{t}\right)
$$

and

$$
y_{t}^{e}=E_{t-1}\left(y_{t}\right)
$$

where $E_{t-1}$ is the conditional expectation operator based on the information available to voters in period $t-1$.

The electoral outcomes are uncertain. For any given $x_{t}^{e}$ and $y_{t}^{e}$, the candidate of party 1 is elected with probability given by

(1.3) $\quad P_{t}=P_{t}\left(x_{t}^{e}, y_{t}^{e}\right)$.

This function can be justified as follows. Each voter votes for the candidate which is expected to implement the policy closest to her bliss point. The uncertainty about electoral results arises because the distribution of voters' preferences is not known with certainty. In particular, the preferences of the median voter are unknown. The function (1.3), then, derives from a probability distribution over possible distributions of voters' preferences, and, in particular, over the bliss point of the median voter. In addition, there might be uncertainty about the number of abstensions. As a result of the uncertainty about the distribution of the costs of voting as perceived by 
different voters ${ }^{6}$.

We make the following assumptions on the election probability function.

(1) The function $\mathrm{P}_{t}(\cdot)$ is time-invariant and "common knowledge".

(2) $0 \leq P \leq I$ for all $x^{e} \in I$ and all $y^{e} \in I$, where $I=[0,1]$.

$$
\begin{aligned}
0<P & <1 \text { for all }\left(x^{e}, y^{e}\right) \in B \text {, where } \\
B & =\left\{(x, y) \in I \times I \mid y^{b} \leq y \leq x \leq x^{b}\right\} .
\end{aligned}
$$

(3) $P\left(x_{t}^{e}, y_{t}^{e}\right)$ is twice continuously differentiable for all $\left(x_{t}^{e}, y_{t}^{e}\right)$ except, possibly, at $x_{t}^{e}=y_{t}^{e}$.

(4) $\frac{\partial P(\cdot)}{\partial x_{t}^{e}}=P_{1}>$ (s) 0 if and only if $x_{t}^{e}<(\geq) y_{t}^{e}$;

$$
\frac{\partial P(\cdot)}{\partial y_{t}^{e}} \equiv P_{2}>(\leq) 0 \text { if and only if } x_{t}^{e} \leq(>) y_{t}^{e} \text {. }
$$

Assumption (4) implies that if one candidate moves toward the other's position, she increases her chances of election by capturing (probabilistically) "middle voters". In other words, the more conservative party always gains by moving toward the left and viceversa. Note that this assumption is restrictive in the sense that it rules out the possibility of entry of a third party for any policy followed by the existing two parties. Assumption ( 1 ) is stronger than is necessary, but simplifies the analysis of the model. It implies that the underlying distribution of voters' preferences is never learned with certainty because, for example, voters preferences change over time and new voters are born. An assumption of time-varying probability functions can be incorporated: the only crucial assumption is that electoral results remain probabilistic. Assumption (3) states that the probability of winning depends smoothly on where the candidates locate, but 
admits the possibility that a discontinuity may arise when the two candidates' positions "cross". As will become apparent from the analysis below, however, it will never be optimal for a candidate to locate in such a way that her opponent's position is between her own position and her ideal point. Hence, this point of discontinuity will never cause any problems in the analysis to follow. It can be shown that a probability distribution of electoral outcomes with these properties can be generated by assuming a known distribution over the bliss point of the median voter.

In the text we consider only the case in which each president can serve only for one term. In the Appendix, we show that this framework can be easily generalized to accomodate multiple terms. 


\section{Electoral Equilibrium}

We first analyze the electoral equilibria in our model when no inter-generational transfers are made. In the absence of such transfers, there is a clear conflict of interest between the "young" vice-president and the "old" president in the sense that every policymaker has incentives to deviate from an optimal ex ante policy once she is elected. To analyze the time consistency problems this poses, suppose that candidates could precommit to their electoral platforms. Then

$$
x_{t}=x_{t}^{a}=x_{t}^{e} \quad \text { and } y_{t}=y_{t}^{a}=y_{t}^{e}
$$

Consider the election held at the beginning of period $t$. If the two candidates "play" Nash against each other, then only the second period matters, since no intergenerational utility transfers are being made and no young agent has any control over the policy adopted while she is either a vice-president or out of office. Hence, the two candidates would solve the following problems (we drop time subscripts for convenience).

$$
\begin{gathered}
\max _{\mathrm{x}} \alpha[\mathrm{P}(\mathrm{x}, \mathrm{y}) \mathrm{U}(\mathrm{x})+(1-\mathrm{P}(\mathrm{x}, \mathrm{y})) \mathrm{U}(\mathrm{y})]+(1-\alpha) \mathrm{P}(\mathrm{x}, \mathrm{y}) \mathrm{k} \\
\max _{\mathrm{y}} \alpha[\mathrm{P}(\mathrm{x}, \mathrm{y}) \mathrm{V}(\mathrm{x})+(1-\mathrm{P}(\mathrm{x}, \mathrm{y})] \mathrm{V}(\mathrm{y})]+(1-\alpha)(1-\mathrm{P}(\mathrm{x}, \mathrm{y})) \mathrm{k} \\
0 \leq \alpha \leq 1 .
\end{gathered}
$$

In (3.2) and (3.3) $\alpha$ represents the relative weights attributed to the 
"ideological goal" versus the goal of simply winning the election (which yields utility $k$ ). The smaller $\alpha$ is, the more Downsian are the two candidates. If (and only if) $\alpha=0$, then the two candidates are interested only in maximizing popularity.

Following Wittman [1983], Calvert [1985], Chapell-Keech [1986], it can be shown that this problem has a unique solution (given the opponent's action) which implies partial or complete convergence, so that the solution $[\hat{x}(y), \hat{y}(x)]$ is such that

$$
x^{b}>\hat{x}(y) \geq \hat{y}(x)>y^{b}
$$

Denoting the Nash equilibrium for the model by $(\hat{x}, \hat{y})$, it can be shown that the distance between $\hat{x}$ and $\hat{y}$ is monotonically decreasing in $k$, and that for each $\alpha$ there exists a value of $k$ (say $k_{0}[\alpha]$ ) such that for $k<k_{0}[\alpha], \hat{x}=\hat{y}$. The candidate of party 1 is then elected with probability $P(\hat{x}, \hat{y})$. The intuition behind these results is straightforward: each candidate converges from her bliss point toward her opponent's position, trading off "ideology" against the increased likelihood of electoral victory.

Now, consider an old president (say from party 1 ) who was elected on the platform $\hat{x}$. Once in office, she has an incentive to break the commitment made when she was a young vice-president. In fact, if the president could break the commitment made as a candidate and reoptimize, she would solve

(3.2a) $\quad \max _{\mathrm{x}} \mathrm{U}(\mathrm{x})$. 
Thus, if precommitment to a platform is unenforcable, the following result is immediate.

Proposition 3.1. For any value of $\alpha>0$, and any finite value of $k$, the electoral equilibrium without precommitment exists, is unique, and is given by $\mathrm{x}=\mathrm{x}^{\mathrm{b}}$ and $\mathrm{y}=\mathrm{y}^{\mathrm{b}}$.

This result is quite strong: since old presidents have no future, when they are in office they have no incentive whatsoever to follow a policy different from their ideal policy. Note also that since presidents cannot be reappointed, there are no reputational mechanisms such as those studied in Alesina [1987a,b] which can enforce any equilibria other than that of Proposition 3.1.

Since voters are rational and forward looking, they will be aware of the dynamic inconsistency problem and will not believe any announcements other than $\mathrm{x}^{\mathrm{a}}=\mathrm{x}^{\mathrm{b}}$ and $\mathrm{y}^{\mathrm{a}}=\mathrm{y}^{\mathrm{b}}$. In this case, the candidate of party 1 is elected with probability $\bar{P}=P\left(x^{b}, y^{b}\right)$.

From our analysis of the time consistency problem, it is clear that the incumbent president and her vice-president will have conflicting views about policy. Since the vice-president must still run for office in her second period of life, she would prefer to precommit the "party" to the strategy $\hat{x}(y)$. As proposition (3.I) makes clear, however, the president will never implement $\hat{x}(y)$. Hence, we are lead to inquire whether there are mechanisms for enforcing precommitment when candidates live finite lives. We will show that this is possible if we allow for intergenerational transfers between vice-president and president. We examine two cases. The first shows how to 
enforce a Nash equilibrium with credible precommitment. In the second, we examine the fully cooperative equilibrium (i.e. the Pareto efficient outcomes).

\section{A] Nash Equilibria with Transfers}

The basic idea behind the transfer mechanism for enforcing precommitment is simple. Young vice-presidents make a utility transfer payment $h(z)$ to the old president. These transfers are a function of the policy followed by the president in office and can be used by the vice-president to convince the president to follow policies which are different from the president's bliss point. By acting without considering the vice-president's wishes, the president can, when in office, always achieve her bliss point. Hence, the amount of the transfer must be sufficient to make the president indifferent between carrying out the vice-president's ex ante preferred policy and the president's bliss point. Hence, for a policymaker of party 1 the amount of the transfer required to make the president indifferent between $\mathrm{x}^{\mathrm{b}}$ and $\mathrm{x}$ is clearly

$$
h(x)=U\left(x^{b}\right)-U(x)
$$

Similarly, for the policymaker of party 2 , the transfer is

$$
\text { (3.5) } \quad g(y)=v\left(y^{b}\right)-v(y)
$$

For the Nash game with transfers, both periods of political life now matter, 
since the vice-president must make a non-zero utility transfer to the president. Hence, the candidates of each party will solve the following optimization problems.

(3.6) $\max _{x} q\{P(x, y)[\alpha[U(x)+h(x))+(1-\alpha) k]+\alpha[1-P(x, y)] U(y)\}-h(x)+U(x)$

(3.7) $\max _{y} q\{[1-P(x, y)][\alpha(V(y)+g(y))+(1-\alpha) k]+\alpha P(x, y) V(x)\}-g(y)+V(y)$.

The first term in braces represents the expected benefits for the second period of life of each candidate, discounted by $q$. The remaining terms represent the total utility of the first period of political life. Since the transfers remove the incentive for deviating from announced policies, the solutions to (3.6) and (3.7) are time-consistent (and hence credible for the voters); thus we can impose the condition that $x^{a}=x^{e}=x$ and $y^{a}=y^{e}=y$. The solutions to these problems are characterized in the following proposition.

Proposition 3.2. If the function $P$ is strictly concave in $x$ and strictly convex in $y$, then solutions exist and are unique. The solutions are given by reaction functions $x^{*}(y)$ and $y^{*}(x)$ such that

$$
y^{b}<y^{*}(x) \leq x^{*}(y)<x^{b}
$$

If $y^{*}(x)<x^{*}(y)$ and $k$ increases, then $x^{*}(y)$ decreases and $y^{*}(x)$ increases. 
Proof: We first show the existence part of the proposition. Note first that we will never have $x^{*}<y^{*}$ since either candidate can, by moving toward the other's position, increase both her "ideological" utility (by moving closer to her ideal point) and the probability of winning the election. Hence, restricting the domains of the expected utilities to policies such that $\mathrm{y} \leq \mathrm{x}$, we see that both candidates objective functions are continuous. Under the assumptions on $\mathrm{P}$, both problems are concave, so by standard concave programming results, solutions exist. When $\mathrm{P}$ is strictly concave in $\mathrm{x}$ and strictly convex in $y$, these solutions are unique.

To show the second part of the proposition, consider the candidate of party 1. Substituting for the function $h(x)$, problem (3.4) becomes

$$
\begin{gathered}
\max _{x} q\left\{P(x, y)\left[\alpha U\left(x^{b}\right)+(1-\alpha) k\right]+\alpha[1-P(x, y)] U(y)\right\}- \\
U\left(x^{b}\right)+2 U(x) .
\end{gathered}
$$

We may assume that $y<x^{b}$. Suppose $x^{*}=x^{b}$ and consider the first-order conditions for the solution to (3.4)

$$
\mathrm{qP}_{1}\left(\mathrm{x}^{\mathrm{b}}, \mathrm{y}\right)\left[\alpha\left(\mathrm{U}\left(\mathrm{x}^{\mathrm{b}}\right)-\mathrm{U}(\mathrm{y})\right]+(1-\alpha) \mathrm{k}\right]+2 \mathrm{U}^{\prime}\left(\mathrm{x}^{\mathrm{b}}\right)=0
$$

Since $U^{\prime}\left(x^{b}\right)=0$, this requires that

$$
\mathrm{qP}_{1}\left(\mathrm{x}^{\mathrm{b}}, \mathrm{y}\right)\left[\alpha\left(\mathrm{U}\left(\mathrm{x}^{\mathrm{b}}\right)-\mathrm{U}(\mathrm{y})\right)+(\mathrm{l}-\alpha) \mathrm{k}\right]=0
$$

Since $q>0, P_{1}\left(x^{b}, y\right)<0$ and the term in brackets is positive, we 
conclude that $x^{*}<x^{b}$. A similar argument establishes that $y^{*}>y^{b}$.

The last part of the proposition follows from a simple comparative static analysis of the first-order conditions associated with problem (3.8)

To establish the existence of a Nash equilibrium, define the mapping

$$
\gamma(x, y)=\left[x^{*}(y), y^{*}(x)\right]
$$

We then have the following result.

Corollary 3.2. The mapping $\gamma$ has a fixed point. Hence, there exists a Nash equilibrium for the game with transfers.

Proof: The mapping $\gamma$ is defined on the set $\{(x, y) \in I \times I \mid y \leq x\}$. This set is compact and convex. By proposition 3.2, $\gamma$ maps this set into itself. Since the solutions to problem (3.8) are continuous in the variables $x$ and $y$ (by the implicit function theorem), it follows that $\gamma$ has a fixed point. Fixed points of $\gamma$ are, of course, Nash equilibria for the game.

Comment 1. The Nash equilibria obtained above are not the only equilibria for the game with transfers, since the sustainability of the equilibria obtained above depends on the fact that the vice-president believes that the transfer will be returned to her if she wins the election. ${ }^{7}$ If the vice-president does not believe the transfer will be returned, then the policies $\left(\mathrm{x}^{\mathrm{b}}, \mathrm{y}^{\mathrm{b}}\right)$ will be the Nash equilibrium policies. (This feature has a close analog in overlapping generations models of money, where the sustainability of an equilibrium with valued fiat money depends on agents' 
believing that money will be valued.)

Comment 2. In the appendix, we show how the analysis of proposition 3.2 must be modified if the president can serve more than one term in office.

\section{B] Cooperative Equilibria with Transfers}

Thus far, we have considered the Nash equilibrium of this game assuming non-cooperative behavior of the two parties. This equilibrium, however, is not on the efficient frontier, i.e. is not a Pareto efficient outcome.

Hence, in this section, we characterize the efficient frontier of the game. We begin by considering the "first-best" policies. These are the cooperative policies which would be followed by infinitely-lived parties which can make binding commitments. To put it differently, the "first-best" policies correspond to the best possible equilibria of the game if we abstract from the problem of enforcement. Then the first-best policies can be achieved without recourse to intergenerational utility transfers, and, as was the case of pre-commitment Nash equilibria, only the expected utility of a candidate in her second period of life matters. In this case, the following can be easily shown.

Proposition 3.3. If $\alpha=1$, then any efficient policy pair $(\bar{x}, \bar{y})$ exhibits full convergence, i.e. $\bar{x}=\bar{y}$. If $\alpha<1$, efficient outcomes involve full convergence and an "agreement" to split k.

Proof: See Alesina [1987a].

Comment. The intuition of this result is straightforward. When $\alpha=1$, 
since candidates are risk averse, they both benefit from full convergence as a means of optimally sharing risk. When $\alpha<1$, candidates must compromise on two issues: ideology and the benefits of being in office. Since any divergence in policies away from full convergence increases risk without enhancing either candidate's chances of being elected, it is clear that the optimal cooperative outcome is to adopt identical policies, together with an agreement on how to share power.

Now we turn to the question of whether there exists a transfer scheme which can support the full cooperative outcome when binding pre-commitments are not possible. We consider first the case of $\alpha=1$, that is the two candidates do not attribute any weight to winning elections per se.

Let us define

(3.11) $\quad \mathrm{EU}[\mathrm{x}, \mathrm{y}]=\mathrm{P}(\mathrm{x}, \mathrm{y})[\mathrm{U}(\mathrm{x})+\mathrm{h}(\mathrm{x})]+[1-\mathrm{P}(\mathrm{x}, \mathrm{y})] \mathrm{U}(\mathrm{y})$

and

$$
E V[x, y]=P(x, y) V(x)+[1-P(x, y)][V(y)+g(y)]
$$

Consider now the problem of finding the cooperative policies for each "generation" of candidates. Each generation has to pay its transfer when young $(h[x]$ and $g[y])$ and it gets $\operatorname{EU}(x, y)$ and $\operatorname{EV}(x, y)$ when old. The best policies sustainable with this transfer scheme can be found by solving the following problem.

(3.13) $\max _{(x, y)} \lambda[q E U(x, y)-h(x)+U(x)]+(1-\lambda)[q E V(x, y)-g(y)+V(y)]$ 
where $0<\lambda<1$.

By substituting from (3.4) and (3.5) for $h(x)$ and $g(y)$ in (3.13), the problem becomes

$$
\max _{(x, y)} \lambda\left[q E U(x, y)-U\left(x^{b}\right)+2 U(x)\right]+(1-\lambda)\left[q E V(x, y)-V\left(y^{b}\right)+2 V(y)\right]
$$

Note also that by using (3.4) and (3.5) we obtain

$$
E U[x, y]=P(x, y) U\left(x^{b}\right)+[1-P(x, y)] U(y)
$$

and

$$
E V[x, y]=P(x, y) V(y)+[1-P(x, y)] V\left(y^{b}\right)
$$

We then have the following characterization of the solutions to (3.14).

Proposition 3.4. If the function $P$ is strictly concave in $x$ and strictly convex in $y$, then solutions to (3.14) exist and are unique for any given value of $\lambda$. The solutions are $\bar{x}, \bar{y}$ such that

$$
y^{b}<\bar{y} \leq \bar{x}<x^{b}
$$

Furthermore, for if $P_{1}(x, y)$ and $P_{2}(x, y)$ are sufficiently close to 0 when $x=y$ then full convergence is not the equilibrium outcome with transfers.

Proof: The proof of existence is exactly as in proposition 3.2, since the assumptions on the probability function $P$ and the fact that it is never optimal to have $\mathrm{x}<\mathrm{y}$ yield a concave programming problem. That $\mathrm{y}^{\mathrm{b}}<\overline{\mathrm{y}}$ and $\overline{\mathrm{x}}<\mathrm{x}^{\mathrm{b}}$ follows from the fact that, by individual rationality, the 
cooperative outcome is at least as good as the Nash equilibrium of corollary 3.2. By proposition 3.2, locating at $\mathrm{y}^{\mathrm{b}}$ (respectively $\mathrm{x}^{\mathrm{b}}$ ) is never a best response to the other candidate's position in the Nash game. Hence, $\mathrm{y}^{\mathrm{b}}$ (respectively $\mathrm{x}^{\mathrm{b}}$ ) cannot be optimal for the cooperative outcome.

To show the second part of the proposition, consider the first-order conditions of problem (3.13).

$$
\begin{aligned}
& \lambda\left\{\mathrm{qP}_{1}(\mathrm{x}, \mathrm{y}) \Delta \mathrm{U}+2 \mathrm{U}^{\prime}(\mathrm{x})\right\}+(\mathrm{I}-\lambda)\left\{-\mathrm{qP}_{1}(\mathrm{x}, \mathrm{y}) \Delta \mathrm{V}+\mathrm{P}(\mathrm{x}, \mathrm{y}) \mathrm{V}^{\prime}(\mathrm{x})\right\}=0 \\
& \lambda\left\{\mathrm{qP}_{2}(\mathrm{x}, \mathrm{y}) \Delta \mathrm{U}+[\mathrm{I}-\mathrm{P}(\mathrm{x}, \mathrm{y})] \mathrm{U}^{\prime}(\mathrm{y})\right\}+(1-\lambda)\left\{-\mathrm{qP}_{2}(\mathrm{x}, \mathrm{y}) \Delta \mathrm{V}+2 \mathrm{~V}^{\prime}(\mathrm{y})\right\}=0
\end{aligned}
$$

where

$$
\Delta \mathrm{U}=\mathrm{U}\left(\mathrm{x}^{\mathrm{b}}\right)-\mathrm{U}(\mathrm{x})
$$

and

$$
\Delta V=V\left(y^{b}\right)-V(y)
$$

Taking ratios yields the single expression

$$
\frac{q P_{1}(x, y) \Delta U+2 U^{\prime}(x)}{q P_{2}(x, y) \Delta U+[1-P(x, y)] U^{\prime}(y)}=\frac{q P_{1}(x, y) \Delta V-P(x, y) V^{\prime}(x)}{q P_{2}(x, y) \Delta V-2 V^{\prime}(y)}
$$

Suppose that $\bar{x}=\bar{y}$ and consider the case where $P_{1}^{+}(x, x)=P_{2}^{-}(x, x)=0$. (Since the function $\mathrm{P}(\cdot)$ may not be differentiable on the diagonal, we consider the right and left derivatives respectively.) Under these assumptions, the ratio above becomes 


$$
\frac{2}{1-P(x, x)}=\frac{P(x, x)}{2}
$$

or

$$
P(x, x)[1-P(x, x)]=4
$$

which is impossible. Hence, for the case where $P_{1}^{+}(x, x)=P_{2}^{-}(x, x)=0$ we have $\bar{x} \neq \bar{y}$. By continuity, it will still be the case that $\bar{x} \neq \bar{y}$ for probability functions having derivatives at $\mathrm{x}=\mathrm{y}$ sufficiently close to 0 .

We now turn to the case of $\alpha \neq 1$. When $\alpha<1$, the cooperative solution must specify a pair of policies $(x, y)$ and a scheme to share the benefits of being in office. Let us define $k_{i}$ as the utility of candidate $i=1,2$ when the two candidates agree to share power. A simple power-sharing scheme might involve an agreement to split the gains of holding office between candidates 1 and 2 in proportions $\delta_{1}$ and $\left(1-\delta_{1}\right)$ when candidate 1 wins, and in proportions $\left(1-\delta_{2}\right)$ and $\delta_{2}$ when candidate 2 wins. These proportions could, for example, represent shares of cabinet positions. Under this scheme, we would have

$$
\mathrm{k}_{1}=\mathrm{k}\left(\dot{\delta}_{1}+\delta_{2}-1\right)
$$

and

$$
\mathrm{k}_{2}=\mathrm{k}\left(\delta_{1}+\delta_{2}-1\right)
$$

It can then be shown ${ }^{8}$ that the optimal cooperative agreement with powersharing is for the candidates to adopt the policies $(\bar{x}, \bar{y})$ obtained for the case of $\alpha=1$, and to negotiate power-sharing proportions $\left(\delta_{1}, \delta_{2}\right)$ such that $\delta_{1}+\delta_{2}=1$

Comment 1. Since the optimal policies depend on the weights $\lambda$ and $(1-\lambda)$, 
a complete determination of the cooperative outcome will depend on the outcome of the bargaining problem agents use to determine which particular efficient policy pair is adopted.

Comment 2. The main implication of Proposition 3.5 is that the transfer scheme will generally not be sufficient to sustain full policy convergence. Intuitively, this result obtains because the effect of the transfer is to guarantee the incumbent president utility equivalent to what she would get in the absence of any transfer, i.e. $U\left(x^{b}\right)$ or $V\left(y^{b}\right)$. Hence, the transfer scheme effectively eliminates the opportunities for risk sharing which drives the convergence result when pre-commitment is possible. The fact that the outcomes achieved by the intergenerational transfer mechanism in general do not exhibit full convergence implies that the model of electoral competition with overlapping generations is not equivalent to a model with infinitely-lived parties. In the model with two infinitely-lived parties, optimal full convergence policies can be sustained as Nash equilibria in an infinitely repeated game if the discount rate $q$ is sufficiently close to 1 (the "folk theorem"). Here, we have shown that the transfer scheme may not be sufficient to obtain full convergence even if $q=1$. To put it differently, the transfer scheme cannot sustain the first-best optimum (full convergence) but can achieve a "second-best", with partial convergence.

Comment 3. We have characterized a cooperative equilibrium in which the two parties maintain their identities in the sense that even though they share power, they do not follow the same policies. This result rationalizes those situations in which representatives of different parties share power in a coalition government, but still tend to follow different policies.

Comment 4. We have assumed so far that individual candidates do not have 
a bequest motive, and hence do not internalize the welfare of future "generations". In this context, a bequest motive is, perhaps, equivalent to caring about how history evaluates your tenure in office. A model with a political bequest motive could be equivalent to a model with infinitely lived policymakers. Barro [1974] has shown this result in a different context. 


\section{Interpretation and Conclusions}

This paper has argued that the "overlapping generations" model can be usefully applied to the political arena. This model captures the potential "tension" between the short time horizon of an individual candidate and the longer horizon of the "party". In fact, a party is formed of overlapping cohorts of individual members and candidates, so that the overlapping generations framework seems a quite natural vehical for analyzing this institution. We believe that the approach of modelling electoral competition using overlapping generations of candidates has many applications which go well beyond the particular one studied in this paper.

In general, the overlapping generations model is a useful tool to analyze many situations involving finitely-live members of an infinitely-lived organization (see also Cremer [1986] on this issue). For the case of a political party, one expects that there will be conflicts between the goals of the individual candidate or elected official at the end of her political life, and the interests of future generations of candidates of the same party. This conflict may assume different forms: we have analyzed one of them, as an example. In particular, we have suggested how: a scheme of intergenerational transfers can enforce policies wich are beneficial for the "party" (and for society as a whole) in the long run, but which would not be followed by any finitely lived individual candidate.

There are at least two ways of interpreting these transfers. The first one is to simply view them as payments in services of various sorts which the president receives if she is well-behaved while in office. These payments may originate from the constituencies which supported her in the past and now are 
supporting her successor(s). They can be enjoyed by the president during her tenure and/or after her retirement.

Alternatively, one may view the party as the institutional mechanism which promotes and facilitates these utility enhancing transfers between its young and old members. The transfers would then be interpreted as "dues" which new party members pay to the party (directly as cash contributions or indirectly as services rendered the party) in exchange for the party's support of their attempts to gain office. Thus, "young members" of the "party" work hard for it, in exchange for the possibility of holding high ranking positions (and the perquisites which attend those positions) later in life, when new young members will work hard for them. 


\section{Appendix}

To complete our discussion of the model, we consider the case where a president can serve more than a single term in office. The model developed in the text, and the results presented there can accomodate this case by assuming that a potential presidential candidate must pay an entry fee to the party in order to become the party's candidate. If the candidate wins, and is subsequently re-elected to a second term, the party returns the entry fee at the completion of the second term. Under the simplifying assumption that incumbent presidents run for re-election on the same platform they were originally elected on, all of the results developed in the text go through for the multi-term case. In this appendix, we indicate how the analysis in proposition 3.2 must be modified when the model is changed to allow the president to serve more than a single term in office.

Under the assumption that the incumbent always runs for re-election on the same platform she was first elected on, we obtain the same optimization problems (and the same solutions) as those given by ( 3.6 ) and (3.7) when the candidates are required to pay an entry fee to the party in order to run for office (except, possibly, for the timing of when the fee is paid). Under the assumption that incumbents always run for re-election on the platform they were first elected on, only the optimization of an incumbent president in her first term is relevant to determining the optimal time-consistent policy. If the entry fee is paid during the president's first term in office, then the relevant optimization problems are precisely (3.6) and (3.7). If the entry fee must be paid in the period during which the candidate first runs for office, then the problem becomes 
(3.6') $\max _{x} q\{P(x, y)[\alpha[U(x)+h(x))+(1-\alpha) k]+\alpha[1-P(x, y)] U(y)\}+U(x)$.

Problem (3.7) is modified similarly. In this case, however, we must append the following condition. Denote the objective function in the above maximization by $E U(x, y ; h)$ and let $E U\left(x^{b}, y\right)$ be the expected utility of the incumbent when she simply adopts her most preferred policy $\mathrm{x}^{\mathrm{b}}$. Then we require that

$$
\mathrm{qEU}(\mathrm{x}, \mathrm{y} ; \mathrm{h})-\mathrm{h}(\mathrm{x}) \geq \mathrm{qEU}\left(\mathrm{x}^{\mathrm{b}}, \mathrm{y}\right)
$$

at the optimal policy with transfer. In words, this constraint requires that when the candidate pays the entry fee, the discounted expected utility of running for office is at least as great as that of not paying the entry fee and simply adopting $x^{b}$. Of course, if the party is in a position to enforce the payment of the entry fee, then this constraint is irrelevant. This situation might occur, for example, when the parties can successfully block independent candidacies and hence, can force candidates to run within party rules. In the context of U.S. presidential politics, such strictures do seem to apply, and we may interpret the entry fee as the costs imposed on candidates by the system of choosing candidates by state primaries. 


\section{Footnotes}

1. The result of policy convergence in a two party system is more general than the median voter theorem, and it holds both in models with perfect or imperfect information about voters' preferences (as long as the two candidates have the same information set). For non-median voter convergence results, see Hinich [1977], Coughlin-Nitzan [1981], Ledyard [1984], Coughlin [1984]. For a general treatment of spatial competition models, see Hinich-Ledyard-Ordeshook [1972, 1973], McKelvey [1975], and the literature cited therein.

2. This result holds if the voters are fully informed about the objective functions of the two parties. The analysis is more complex in the case of asymmetric information. (See Alesina and Cukierman [1987].) Note also that if there are multiple one-shot Nash equilibria, recent work by Benoit and Krishna [1985] and Friedman [1985] shows that it may be possible to sustain partial cooperation in a finite-horizon game without the kinds of transfers we propose here.

3. Analogous considerations would hold for other countries as well. For example, the English economy may have suffered because of the significant differences in the economic policies of the Labour Party and the Conservative Party.

4. Lott-Reed [1987] analyze a last-period problem for politicians but in a different context. In particular, they do not consider the overlapping 
sequence of candidates.

5. Extensions of the model allowing for different $k^{\prime} s$ and $q^{\prime} s$ are computationally cumbersome and add very little to the basic results.

6. Ledyard [1984] derives a function analogous to (1.3) from the uncertainty about costs of voting. A representation of voting behavior analogous to (1.3) is also postulated by Wittman [1983], Calvert [1985], Alesina [1987a], and Chape11-Keech [1986].

7. We are grateful to Costas Azariadis for pointing out this possibility to us .

8. Proof of this assertion is available from the authors. 


\section{References}

Alesina, Alberto, (1987a), "Credibility and Policy Convergence in a Two-Party System with Rational Voters", unpublished manuscript.

Alesina, Alberto, (1987b), "Macroeconomic Policy in a Two-Party System as a Repeated Game", Quarterly Joumal of Economics, forthcoming.

Alesina, Alberto and Alex Cukierman, (1987), "Asymmetric Information and Policy Convergence in a Two-Party System", in preparation.

Alesina, Alberto and Jeffrey Sachs, (1988), "Political Parties and the Business Cycle in the United States, 1968-1986", Journal of Money, Credit and Banking, forthcoming.

Alesina, Alberto and Guido Tabellini, (1987), "Credibility and Politics", unpublished manuscript.

Barro, Robert, (1974), "Are Government Bonds Net Wealth?", Journal of Political Economy, 62, 1035-1118.

Benoit, Jean-Pierre, and Vijay Krishna, (1985), "Finitely Repeated Games", Econometrica, 53, 905-923.

Calvert, Randa11, (1985), "Robustness of the Multi-dimensional Voting Model; Candidate Motivations, Uncertainty and Convergence", American Journal of Political Science, vol. XXIX, 69-95.

Chapell, Henry and William Keech, (1986), "Policy Motivation and Party

Differences in a Dynamic Spatial Model of Party Competition", American Political Science Review, 79, 10-27.

Coughlin, Peter and Samuel Nitzan (1981), "Directional and Local Equilibria with Probabilistic Voting", Journal of Economic Theory, 24, 226-239. Cremer, Jacques, (1986), "Cooperation in On-going Organizations", Quarterly 
Journal of Economics, vol. 101, 33-50.

Downs, Anthony, (1957), An Economic Theory of Democracy, Harper, New York. Friedman, James, (1985), "Cooperative Equilibria in Finite Horizon

Non-cooperative Supergames", Joumal of Economic Theory, 35, 330-358.

Hibbs, Douglas (1987), "The American Political Economy: Electoral Policy and

Macroeconomics in Contemporary America", Cambridge, Ma., Harvard

University Press, forthcoming.

Hinich, Melvin, (1977), "Equilibrium in Spatial Voting: The Median Voter

Result is an Artifact", Journal of Economic Theory, 16, 208-219.

Hinich, Melvin, John Ledyard and Peter Ordeshook, (1973), "A Theory of

Electoral Equilibrium: A Spatial Analysis Based on the Theory of Games", Journal of Politics, 35, 134-193.

Hinich, Melvin, John Ledyard, and Peter Ordeshook, (1972), "Non-voting and the Existence of Equilibrium Under Majority Rule", Journal of Economic Theory, $14,144-153$

Kotlikoff, Lawrence, Torsten Persson, and Lars Svensson, (1986), "Laws as Assets", unpublished manuscript.

Ledyard, John, (1984), "The Pure Theory of Large Two-Candidate Elections", Public Choice, 7-41, August.

Lott, John R. and W. Robert Reed, (1987), "Shirking and Sorting in a Political Market with Finite-Lived Politicians", mimeo.

McKelvey, Richard, (1975), "Policy Related Voting and Electoral Equilibrium", Econometrica, 43, 815-863.

Wittman,--Donald, (1977), "Candidates with Policy Preferences: A Dynamic

Model", Journal of Economic Theory, vol. XIV, 180-189, February.

Wittman, Donald, (1983), "Candidate Motivation: A Synthesis of Alternatives", 
American Political Science Review, vol. LXXVI, 142-157. 